\title{
Logistic Surplus-Production Model with Explicit Terms for Growth, Mortality, and Recruitment
}

\author{
A. L. JENSEN \\ School of Natural Resources \\ University of Michigan \\ Ann Arbor, Michigan 48109
}

\begin{abstract}
Conventional interpretations of the logistic equation and the logistic surplus-production model appear to indicate that regulation of population size occurs as a result of competition for resources among the recruited members of a population. Compensation for fishing mortality may involve increased growth of adults and an increase in fecundity, but the major compensatory factor is increased survival of early life stages. In this study, the logistic surplus-production model is formulated in explicit terms for growth, reproduction, and mortality, and in this new formulation the capacity of a population to increase and sustain a fishery is based on a stock-recruitment relation that is a more realistic interpretation of fishery dynamics. All parameters can be estimated with catch and effort data. The models were applied to the American lobster Homarus americanus fishery in Maine and the spiny dogfish Squalus acanthias fishery. There is a considerable difference in the stock-production curves between the two fisheries that can be interpreted in terms of a similar difference in the spawner-recruit curves. Because spiny dogfish produce relatively few young, they have a lower potential for increase than American lobsters and their rate of recruitment does not increase with exploitation as greatly as that for lobsters.
\end{abstract}

Received July 2, 1983

Accepted June 21, 1984

Surplus-production models provide a simple means for description of the dynamics of exploited populations in terms of a density-dependent compensatory response to fishing, they are relatively easy to study analytically, and they often can be applied for stock assessment with only catch and effort data. These are good reasons for application of surplus-production models. However, with surplus-production models, the dynamics of a population are described in terms of vague notions of a carrying capacity and a coefficient for increase. The capacity of a population to increase is some function of population size; a maximum capacity for increase occurs at an intermediate population size, which appears to indicate that compensation for exploitation occurs during the recruited life stages. Exploitation may result in a decrease in natural mortality of recruits, an increase in growth of recruits, and an increase in fecundity, but increased survival of early life stages is the major compensatory mechanism (Beverton and Holt 1957; Ricker 1975).

The logistic model can be interpreted in several different ways and some interpretations are consistent with the observed dynamics of fish- eries. Walter (1978) developed a surplus-production model that incorporates a recruitment function and that gives a more realistic description of the compensatory dynamics of a fish population in terms of a spawner-recruit curve, but to apply his model, data for recruitment as well as for catch and effort are necessary. Recruitment data are available for few fisheries and when they are, age-structure data also are likely to be available and a surplus-production model usually would not be applied. Deriso (1980) developed a yield equation that gives change in biomass in terms of growth, recruitment, and mortality; his model has some features in common with surplus-production models but it is a discrete-time model.

It is shown in this study that the logistic surplus-production model can be interpreted in terms of explicit components for growth, mortality, and recruitment and that all of the parameters can be estimated from catch and effort data. The model is applied to describe the dynamics of fisheries for American lobster Homarus americanus and spiny dogfish Squalus acanthias. The life histories of these two species are different and a comparison of the models fitted 
to these two species provides an evaluation of the ability of the models to distinguish differences in spawner-recruit relations.

\section{Model Development}

For surplus-production models, the capacity of a population to increase is some function of population size and the maximum capacity to increase occurs at some intermediate population size. A commonly applied surplus-production model is the logistic model developed by Volterra (1928), Graham (1935), and Schaefer (1954, 1957), described by the equations

$$
\begin{aligned}
& \mathrm{d} Y / \mathrm{d} t=q E B \text { and } \\
& \mathrm{d} B / \mathrm{d} t=k B-k B^{2} / B_{\infty}-q E B ; \\
Y= & \text { cumulative yield; } \\
t= & \text { time; } \\
B= & \text { biomass of the exploited part of the } \\
& \text { population; } \\
B_{\infty}= & \text { environmental carrying capacity in } \\
& \text { terms of biomass; } \\
k= & \text { population growth coefficient; } \\
q= & \text { catchability coefficient; } \\
E= & \text { fishing effort. }
\end{aligned}
$$

Under equilibrium conditions where $\mathrm{d} B / \mathrm{d} t=$ 0 , the relation between annual equilibrium yield $Y$, and biomass is the parabola

$$
Y_{e}=k B-k B^{2} / B_{\infty}
$$

and the relation between annual equilibrium yield and effort is the parabola

$$
Y_{e}=q B_{\infty} E-\left(q^{2} B_{\infty} / k\right) E^{2} .
$$

The logistic surplus-production model indicates that a maximum sustainable yield MSY of $k B_{\infty} / 4$ occurs at a biomass of $B_{\infty} / 2$ and a fishing effort of $k / 2 q$. Useful modifications of the logistic surplus-production model have been suggested by Pella and Tomlinson (1969), Fox (1970), Walter (1973, 1978), and Marchesseault et al. (1976).

Russell (1931) described the change in abundance of an exploited fish stock in terms of a balance among natural mortality, recruitment, growth, and fishing mortality using the equation

$$
\begin{aligned}
B(t)= & B(t-1)+R+G-F-M ; \\
B(t)= & \text { biomass of the catchable stock at } \\
& \text { time } t \\
B(t-1)= & \text { biomass of the catchable stock at } \\
& \text { time }(t-1) ;
\end{aligned}
$$

$$
\begin{aligned}
R= & \text { increase in biomass of the catch- } \\
& \text { able stock through recruitment; } \\
G= & \text { increase in biomass of the catch- } \\
& \text { able stock through growth of in- } \\
& \text { dividuals from time } t \text { to } t+1 ; \\
F= & \text { loss of biomass from the popu- } \\
& \text { lation through fishing; } \\
M= & \text { loss of biomass from the popu- } \\
& \text { lation through natural mortality. }
\end{aligned}
$$

In Equation (5), the change in stock biomass equals recruitment plus growth minus natural and fishing mortality. If change in growth, natural mortality, and fishing mortality are assumed proportional to stock size, Russell's model can be written as

$$
\begin{aligned}
\mathrm{d} Y / \mathrm{d} t & =q E B \text { and } \\
\mathrm{d} B / \mathrm{d} t & =(K-M) B+R(t)-q E B,
\end{aligned}
$$

where the new terms are

$$
\begin{aligned}
K= & \text { parameter for increase in biomass re- } \\
& \text { sulting from growth in size of indi- } \\
& \text { viduals; } \\
M= & \text { natural mortality coefficient; } \\
R(t)= & \text { biomass of recruitment at time } t .
\end{aligned}
$$

Equations (6) and (7) form a general surplusproduction model that includes many other models as special cases. First the case with constant recruitment will be considered. With constant recruitment, Equation (7) predicts that biomass of an unfished population will converge to $R_{c}(M-K)^{-1}$ and this is the carrying capacity; $R_{c}$ is a constant rate of recruitment. At any level of fishing such that $(M+q E)>K$, population biomass will converge to $R_{c} /(M-K+q E)$. Under equilibrium conditions, the relation between annual equilibrium yield and biomass is the linear equation

$$
Y_{e}=R_{c}+(K-M) B .
$$

This is the equation for equilibrium yield given by Russell (1931). The stock-production curve is a line that decreases from $R_{c}$ at $B=0$ to zero at $B=R_{c} /(M-K)$ provided that $M<K$.

If recruitment is constant, the relation between annual equilibrium yield and fishing effort is the asymptotic equation

$$
Y_{e}=q E R_{c} /(M-K+q E) .
$$

The asymptote is recruitment $R_{c}$. The model predicts no maximum yield; yield increases toward an asymptote as effort increases and the 


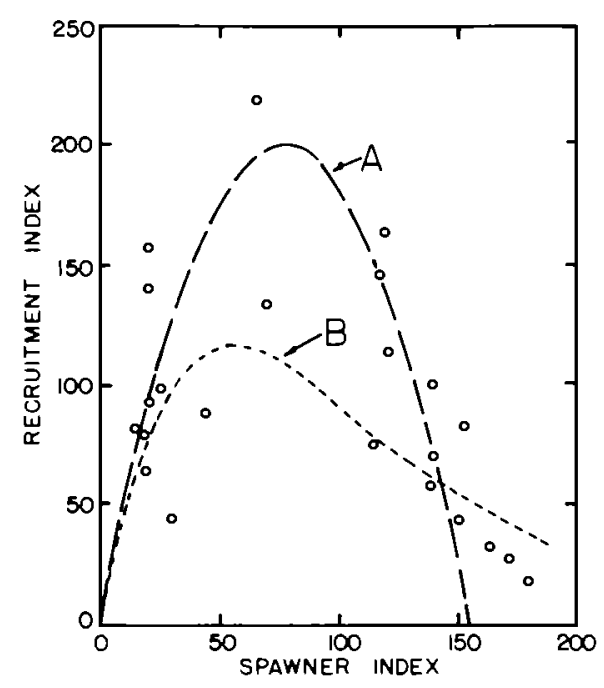

FIGURE 1.-Spawner-recruit data for Atlantic cod 19381960 and (A) parabolic and (B) Ricker spawner-recruit functions.

highest yields from the fishery occur when the level of fishing is intense and the population consists of newly recruited individuals. This is the same relation obtained with the dynamicpool model when natural mortality is high and recruitment is constant (Beverton and Holt 1957).

Recruitment often is assumed to be a function of population size, increasing to a maximum at an intermediate level of stock biomass and then decreasing with further increase in biomass. Ricker's (1954) spawner-recruit relation between recruitment at time $t$ and biomass at time $\left(t-t_{m}\right)$, where $t_{m}$ is the age at maturity, is

$$
R=a B\left(t-t_{m}\right) e^{-h B\left(t-t_{m}\right)},
$$

where $a$ and $h$ are parameters. This is a flexible function that describes the pattern but a parabola gives a similar pattern and leads to the logistic surplus-production model. A surplus-production model could be formulated based on Ricker's model but Ricker's model is difficult to handle mathematically. The parabola can be considered an approximation to Ricker's function; the series expansion of the exponential term of Ricker's model is

$$
e^{-h B}=\sum_{i=0}^{\infty}(-h B)^{i} / i !
$$

and for an approximation with $i=1$, Ricker's

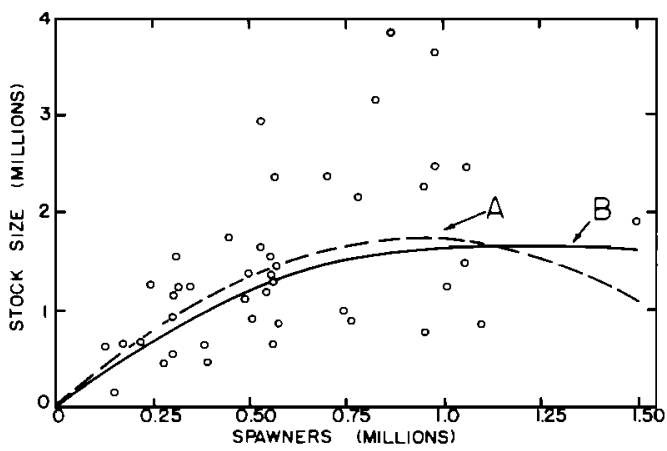

FIGURE 2.-Spawner-recruit abundance for Skeena River sockeye salmon 1908-1952 and (A) parabolic and (B) Ricker spawner-recruit functions.

recruitment equation becomes the parabola

$$
R=a B\left(t-t_{m}\right)-b B\left(t-t_{m}\right)^{2},
$$

where $b$ is a parameter. For some species for which the number of spawners and recruits or spawner and recruit indices are available, a parabola fits about as well as Ricker's model. To demonstrate this, a parabola and Ricker's model both were fitted by least squares to the spawner-recruit data for Skeena River sockeye salmon Oncorhynchus nerka published by Shepard and Withler (1958) and to the data for Atlantic cod Gadus morhua published by Garrod (1967). For both of these populations, there is considerable scatter, as is typical of spawner-recruit data, and the parabola fits about as well as Ricker's model (Figs. 1 and 2).

If recruitment is described by a parabola, the surplus-production model (Equations 6 and 7) becomes

$$
\begin{aligned}
\mathrm{d} Y / \mathrm{d} t= & q E B \\
\mathrm{~d} B / \mathrm{d} t= & (K-M) B^{2}+a B\left(t-t_{m}\right) \\
& -b B\left(t-t_{m}\right)^{2}-q E B,
\end{aligned}
$$

which is a logistic surplus-production model with a time lag and it is similar to the model suggested by Marchesseault et al. (1976). Estimation of parameters for surplus-production models is difficult and the above model cannot be easily fitted with only catch and effort data, so recruitment is assumed to be instantaneous; then the model becomes

$$
\begin{aligned}
\mathrm{d} y / \mathrm{d} t & =q E B \\
\mathrm{~d} B / \mathrm{d} t & =(K-M+a) B-b B^{2}-q E B,
\end{aligned}
$$


which is a logistic surplus-production model. However, the parameters now have a different interpretation; in Equation (16) the density dependence operates through the spawner-recruit relation and the rate of recruitment is a maximum at some intermediate population size.

Although the model with a time lag describes the recruitment process more accurately and may be better for forecasting, surplus-production models usually are applied for equilibrium analyses and, in this situation, the above two models become nearly identical. Some time-lag models result in different behavior from the logistic model (Marchesseault et al. 1976), whereas other models result in behavior similar to the logistic provided that the time lag is not too long (Hutchinson 1948; Walter 1973). Further study is necessary to determine which timelag models better describe the dynamics of fish populations.

The equilibrium population size for a population described by Equation (16) can be determined from the spawner-recruit relation or from the equation for change in biomass. There is a replacement level of biomass $B^{*}$ for an unexploited fishery such that at $B^{*}$ the population is at equilibrium and $R^{*}=c B^{*}$, where $c$ is a parameter and $R^{*}$ is recruitment at equilibrium. The level of recruitment at equilibrium without exploitation can be calculated from the spawner-recruit curve as

$$
R^{*}=c B^{*}=a B^{*}-b\left(B^{*}\right)^{2},
$$

which gives the equilibrium biomass in terms of the parameters as

$$
B^{*}=(a-c) / b \text {. }
$$

If a population is not exploited, it will maintain itself at $B^{*}$ and from the biomass equation (Equation 16), when $\mathrm{d} B / \mathrm{d} t=0$ and $B=B^{*}$, the equation

$$
B^{*}=(a-M+K) / b
$$

is obtained. Comparison of Equations (17) and (18) shows that the parameter $c$ equals $M-K$. Recruitment in an unexploited population is

$$
R^{*}=\left[a(M-K)-(M-K)^{2}\right] / b
$$

and a maximum recruitment of $a^{2} / 4 b$ occurs at a biomass of $a / 2 b$.

If the dynamics of a fishery are described by Equations (15) and (16) the relations between yield and biomass and between yield and effort, as well as between recruitment and biomass, are all parabolas. At equilibrium where $\mathrm{d} B / \mathrm{d} t=0$, the relation between annual equilibrium yield and biomass is

$$
Y_{e}=(a-M+K) B-b B^{2}
$$

and the maximum yield, $(a-M+K)^{2} / 4 b$, occurs at a biomass of $B_{m s y}=(a-M+K) / 2 b$. The MSY occurs when recruitment is

$$
R_{m s y}=\left[a^{2}-(K-M)^{2}\right] / 4 b .
$$

The relation between annual equilibrium yield and fishing effort is the parabola

$$
Y_{e}=(K-M+a) q E / b-q^{2} E^{2} / b .
$$

\section{Parameter Estimation}

Estimation of parameters of surplus-production models is difficult, especially if biomass is not proportional to annual catch per unit of effort (Bannerot and Austin 1983). This brings into question estimation methods that linearize the yield equation and then approximate biomass in terms of catch per unit of effort (for example, Schnute 1977). Numerical integration of the yield equation and nonlinear least squares, as suggested by Pella and Tomlinson (1969), avoids the need to assume biomass is proportion to annual catch per unit of effort. To apply the Pella and Tomlinson (1969) method, it is helpful to use a biomass equation that can be integrated in closed form and this makes it impossible to consider time lags.

To estimate parameters of the logistic model with explicit parameters for growth, mortality, and recruitment, both the model with constant recruitment and the model with a parabolic spawner-recruit function are fitted to the catch and effort data. The constant-recruitment model provides an estimate of $K, M$, and the average recruitment and is a base from which the relation between stock and recruitment can be measured. All of the parameters can be estimated for the logistic model, the asymptotic model, and the model with a spawner-recruit relation. Parameters of both the logistic and asymptotic model were estimated with nonlinear least squares to fit the solutions of the yield equations to observed yields. Application of the trapezoidal rule to the yield equation gives the estimated yields as (Pella and Tomlinson 1969) 


$$
\begin{aligned}
Y(t) & =q E(t) \int_{t}^{t+1} B(y) \mathrm{d} y \\
& =q E(t)[B(t+1)+B(t)] / 2 .
\end{aligned}
$$

For the logistic model biomass values were calculated from the solution to the biomass equation (Equation 2)

$$
\begin{aligned}
B(t)= & \left\{\frac{k}{B(k-q E)}\right. \\
& \left.+\left[\frac{1}{B(0)}-\frac{k}{B(k-q E)}\right] e^{-(k-q E) t}\right\}^{-1} .
\end{aligned}
$$

For the asymptotic model, biomass values were calculated from the solution of the biomass equation (Equation 16)

$$
\begin{aligned}
B(t)= & \frac{R}{M+q E-K}\left[1-e^{(K-M-q E) t}\right] \\
& +B(0) e^{(K-M-q E) t} .
\end{aligned}
$$

For the logistic model, the values of the parameters $k, q$, and $B_{\infty}$ that minimized the residual sum of squares

$$
\sum_{t}[Y(t)-Y(t)]^{2}
$$

was found, and for the asymptotic model, the values of the parameters $q, R_{c}$, and $(K-M)$ that minimized the residual sum of squares was found.

Application of the above method gives estimates of $k, B_{\infty}$, and $q$ for the logistic model and $(K-M), R_{c}$ and $q$ for the asymptotic model. From these estimates the parameters of the spawner-recruit model were estimated as

$$
\begin{aligned}
b & =k / B_{\infty} \text { and } \\
a & =k-c=k+(K-M) .
\end{aligned}
$$

The term $(K+M)$ can be calculated with the equation

$$
K+M=b R^{*} / a(M-K),
$$

which is obtained from the equation for $R^{*}$ at equilibrium (Equation 19), and then from the estimated values of $(M-K)$ and $(M+K)$, the values of $M$ and $K$ can be estimated.

\section{Results and Discussion}

To evaluate the surplus-production model formulated in terms of a spawner-recruit relation, the logistic surplus-production model, the asymptotic model, and the model with a spawner-recruit relation were applied to describe the
American lobster fishery of Maine and the spiny dogfish fishery of the North Sea (all subsequent references to "lobster" and "dogfish" refer to these species). These fisheries were selected because a long series of catch and effort data are available for each, and the biology and life histories of lobsters and dogfish are considerably different. Dow et al. (1975) described the lobster fishery and gave catch and effort data for 1928 to 1972; Holden (1977) described the dogfish fishery and gave catch and effort data for 1951 to 1970.

Application of parameter estimates (Table 1) for the logistic and asymptotic surplus-production models, obtained by fitting the catch and effort data with nonlinear least squares, together with the relations given by Equations (27), (28), and (29), gives the estimates of the parameters $M$ and $K$ of the asymptotic model and the parameters of the spawner-recruit model. Population quantities then were derived from these parameters together with the equations of the previous section (Table 1).

Statistical evaluation of the parameter estimates of surplus-production models is difficult; a valid analysis would consider the nonlinearity of the models and correctly model the random variables. Statistical theory for such models is limited (Draper and Smith 1980), and, in this study, accuracy of the parameter estimates was judged qualitatively in terms of how well the fitted models described the observed catch and effort data, in terms of the relations among parameters, and in terms of the relations of certain parameters, such as the carrying capacity, to the observed catch and effort data.

Both the logistic and asymptotic models described the trends in the lobster catch data (Fig. 3 ), but both models overestimated catch during the early years and underestimated catch from 1950 to 1960 . For lobster, the coefficients of determination between observed and predicted yields were high: 0.84 for the logistic model and 0.82 for the asymptotic model. The logistic and asymptotic models also describe the pattern of fluctuations in the dogfish fishery (Fig. 4) but the coefficients of determination are lower than for the lobster: 0.22 for the logistic model and 0.20 for the asymptotic model. Some of the differences in the coefficients of determination between the lobster and dogfish fisheries result from the increase in yield of lobsters, which gives a high slope; the coefficient of determi- 


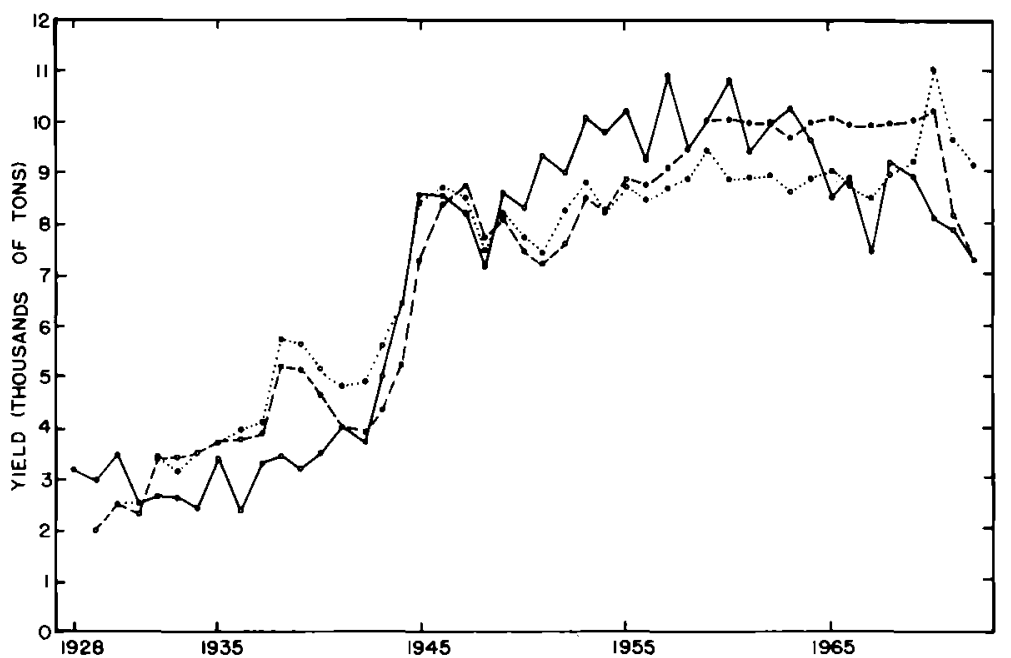

FIGURE 3.-Observed Maine American lobster catch (solid line) and predictions of logistic model (dashed line) and asymptotic model (dotted line).

nation is influenced both by the slope of a relation and by the scatter of observations about the predicted values (Draper and Smith 1980).

For both fisheries, the estimates of the catchability coefficients were the same for the logistic model and the asymptotic model. The carrying capacities of both fisheries are reasonable when compared to yield; for the lobster fishery the MSY is $25 \%$ of population size at the MSY and for the dogfish fishery the MSY is $26 \%$ of population size. The average recruitment $R_{c}$ obtained with the asymptotic model is consistent with the values obtained with the spawner-recruit relation $R_{m s y}($ Table 1). The recruitment

TABLE 1.-Estimated surplus-production parameters and population quantities calculated from these for the Maine American lobster and North Sea spiny dogfish fisheries.

\begin{tabular}{|c|c|c|c|c|}
\hline \multicolumn{3}{|c|}{ Parameter or quantity } & \multirow{2}{*}{$\begin{array}{c}\text { American } \\
\text { lobster }\end{array}$} & \multirow{2}{*}{$\begin{array}{c}\text { Spiny } \\
\text { dogfish }\end{array}$} \\
\hline Symbol & Term & Unit & & \\
\hline \multicolumn{5}{|c|}{ Parameters estimated directly by nonlinear model fits to catch-effort data } \\
\hline $\begin{array}{l}k=a-c \\
B\end{array}$ & $\begin{array}{l}\text { Population growth coefficient } \\
\text { Biomass of exploited population }\end{array}$ & Tonnes & $\begin{array}{c}0.50 \\
8 \times 10^{4}\end{array}$ & 0.50 \\
\hline$q$ & Catchability coefficient & 50 & $0.3 \times 10^{-6}$ & $0.5 \times 10^{-5}$ \\
\hline$c=M-K$ & Equilibrium recruitment parameter & & 0.03 & 0.07 \\
\hline$R_{c}$ & Constant recruitment & Tonnes & 10,000 & 42,000 \\
\hline \multicolumn{5}{|c|}{ Parameters estimated from above quantities } \\
\hline$M$ & Natural mortality coefficient & & 0.50 & 0.50 \\
\hline$K$ & Growth coefficient, individuals & & 0.47 & 0.43 \\
\hline$b$ & Recruitment parameter & & $6.25 \times 10^{-6}$ & $1.67 \times 10^{-6}$ \\
\hline$a$ & Recruitment parameter & & 0.53 & 0.57 \\
\hline \multicolumn{5}{|c|}{ Quantities estimated from above parameters } \\
\hline$B_{\max R}$ & Biomass at maximum recruitment & Tonnes & 42,400 & 170,966 \\
\hline$R_{\max }$ & Maximum recruitment & Tonnes & 11,236 & 48,725 \\
\hline$R^{*}$ & Equilibrium recruitment & Tonnes & 2,400 & 20,970 \\
\hline$B^{*}$ & Equilibrium biomass & Tonnes & 80,000 & 300,000 \\
\hline$B_{\text {msy }}$ & Biomass at maximum yield & Tonnes & 40,000 & 150,000 \\
\hline \multirow[t]{2}{*}{$E_{\mathrm{msy}}$} & Effort at maximum yield & Traps & 833,333 & \\
\hline & & Hours & & 500,000 \\
\hline MSY & Maximum sustainable yield & Tonnes & 10,000 & 37,500 \\
\hline$R_{\text {msy }}$ & Recruitment at maximum yield & Tonnes & 11,200 & 47,990 \\
\hline
\end{tabular}




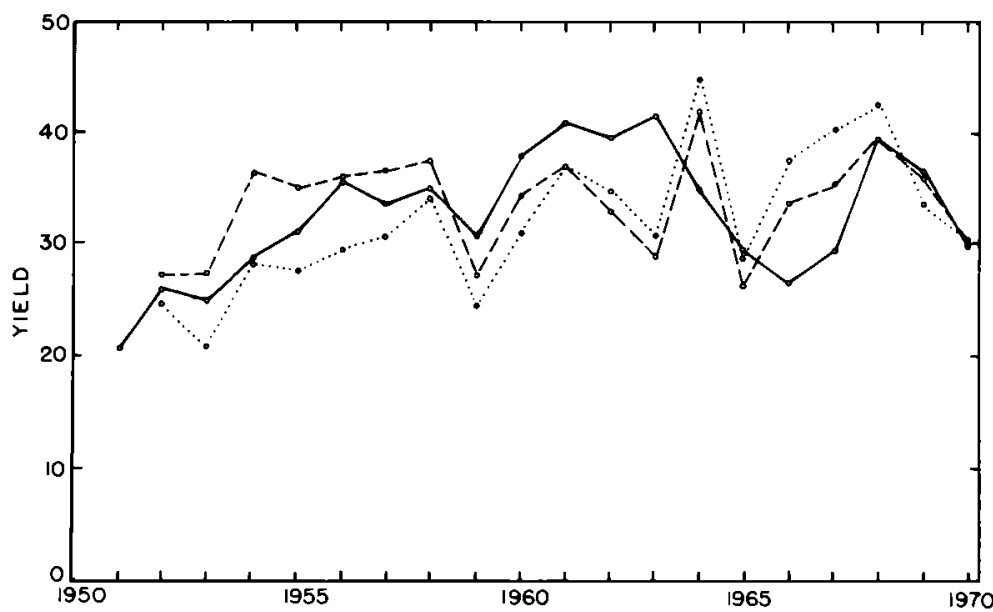

FIGURE 4.-Observed spiny dogfish catch in thousands of metric tons (solid line) and predictions of logistic model (dotted line) and asymptotic model (dashed line).

estimates obtained with the spawner-recruit relation are of considerable interest (Table 1). Recruitment in an unexploited lobster population would be only $3 \%$ of the standing stock. At the MSY, lobster recruitment is $26 \%$ of the standing stock. Recruitment in an unexploited dogfish population also would be low but at $7 \%$ of the standing stock it would be nearly twice as high, relative to stock size, as lobster recruitment. At the MSY, dogfish recruitment is about $28 \%$ of the standing stock.

The equilibrium stock-production curves of both the asymptotic model and the logistic model fit the catch and effort data for both the dogfish and the lobster fishery (Figs. 5 and 6), but for the lobster fishery the catch clearly has decreased at high effort and the logistic model describes the pattern better than the asymptotic model. For the dogfish fishery, catch has not decreased with high effort and the asymptotic and logistic models describe the pattern about equally as well. With the logistic model, the MSY for the lobster fishery is $10,000 \mathrm{t}$ at a fishing effort of 833,333 traps, and for the dogfish fishery the MSY is $35,700 \mathrm{t}$ at a fishing effort of 500,000 hours. The effort applied to the lobster fishery has exceeded the level that should produce the MSY and yield has increased to a maximum and begun to decrease as predicted by the model; however, the dome of the equilibrium stock-production curve appears too high and overestimates the MSY. For the dogfish fishery, fishing effort also has gone beyond the level that should produce the MSY, but there is not a clear peak in the observed catch and effort data. The asymptotic stock-production curve fits the dogfish data about as well as the logistic model, which might indicate that either the capacity of dogfish populations to increase is not closely density-dependent or the population does not have a large reproductive reserve.

Dogfish produce only a relatively small number of young and the spawner-recruit relations for dogfish and lobster are very different (Figs. 7 and 8). For the lobster population, as biomass decreases below the equilibrium-level, recruitment increases sharply and the maximum level

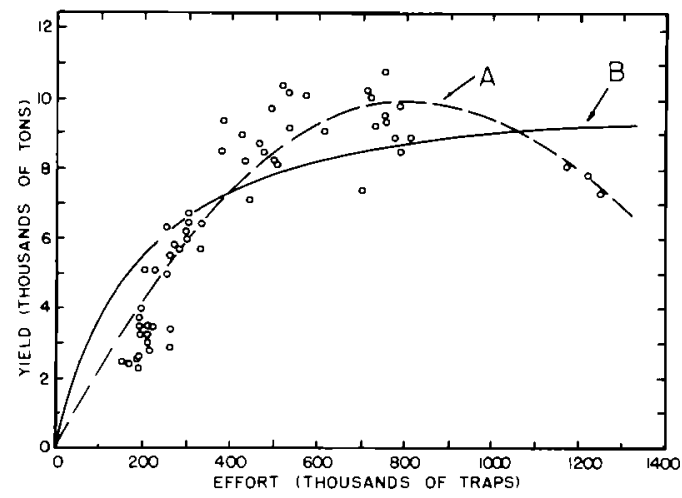

Figure 5.-Catch and effort data for Maine American lobster 1928-1972 and equilibrium stock-production curves for (A) logistic model and $(B)$ asymptotic model. 


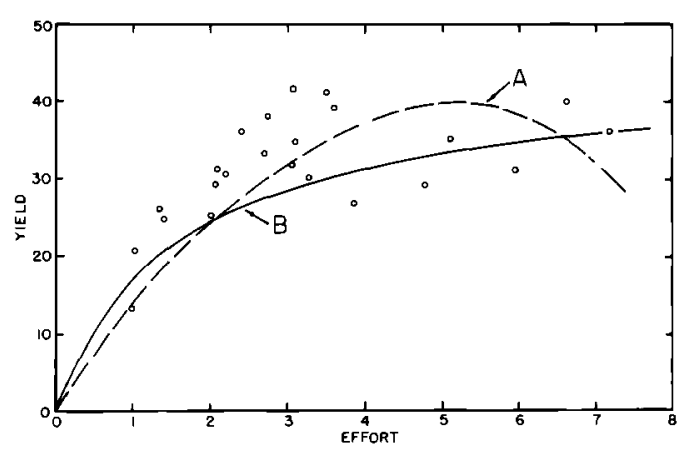

FIGURE 6.-Catch and effort data for spiny dogfish 19511970 and (A) logistic equilibrium stock-production curve and (B) asymptotic stock-production curve. Yield is in thousands of tonnes and effort is hundreds of thousands of hours.

of recruitment is more than five times the level of recruitment without fishing. At the MSY, yield is nearly equal to recruitment. The lobster fishery is sustained largely by new recruits (Dow et al. 1975). The maximum recruitment for dogfish is only a little more than twice the level of recruitment at equilibrium without a fishery. Many models for biomass change can be developed from the relation among change in biomass, natural mortality, fishing mortality, and growth formulated by Russell (1931). The capacity of the logistic surplus-production model to describe the general pattern of growth of populations has been well established in applications of the surplus-production model to nat-

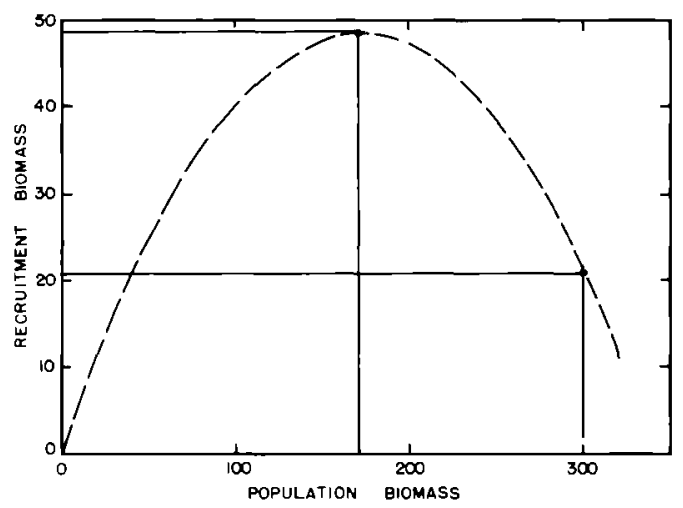

FIGURE 7.-Spiny dogfish spawner-recruit relation estimated from logistic surplus-production model. Recruitment and population biomass are in thousands of tonnes. The points indicate the maximum recruitment and recruitment at equilibrium without fishing.

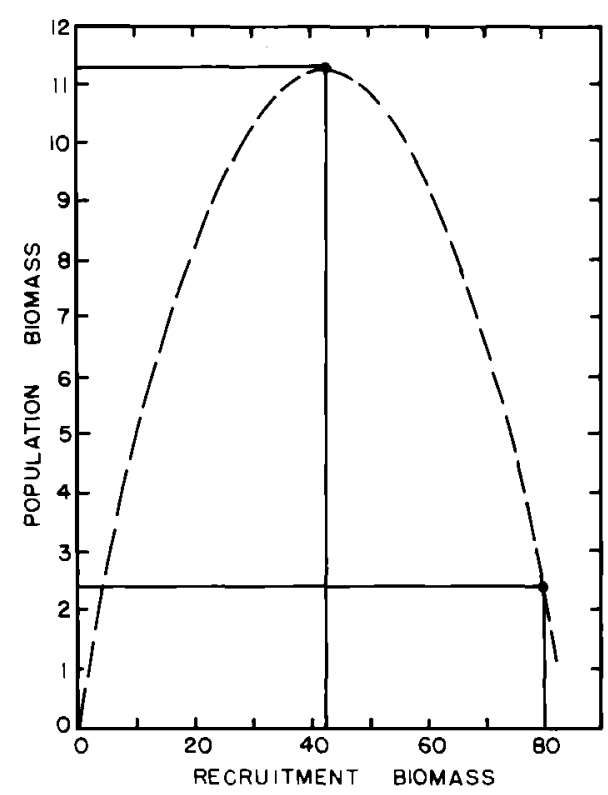

FIGURE 8.-American lobster spawner-recruit relation estimated from logistic surplus-production model. Recruitment and population biomass are in thousands of tonnes. The points indicate the maximum recruitment and recruitment at equilibrium without fishing.

ural populations (for example, Schaefer 1954, 1957; Ricker 1975; Jensen 1976, 1978) and in laboratory experiments (Silliman and Gutsell 1958; Silliman 1968, 1971, 1972; Jensen and Marshall 1982, 1983); therefore, a reasonable approach for development of a model with explicit terms for the components of yield is to formulate the logistic equation in terms of growth, reproduction, and mortality.

Interpretation of the logistic surplus-production model in terms of a recruitment function describes the capacity of a population to increase and support a fishery in terms of an increase in recruitment that occurs with a decrease in population size. In an unexploited stock, a population fluctuates about a carrying capacity that is also the population size for equilibrium between stock and recruitment. Exploitation increases mortality, which decreases stock size; as exploitation increases, stock size decreases and recruitment increases to a maximum and then begins to decrease. The capacity of a population to increase and to support a fishery results from the relation between abundance of spawners and recruitment. This is a more realistic description of the dynamics of an 
exploited fish population than is given by the usual interpretation of the logistic surplus-production model. The two descriptions are not incompatible; the usual formulation of the logistic equations assumes that there is densitydependent regulation of population size but it does not describe the mechanism.

\section{Acknowledgments}

I thank G. W. Fowler and R. L. Patterson for comments on an earlier draft of this work; their comments and those of several others led to a substantial revision and a much improved analysis. I also thank two anonymous reviewers of this paper for many improvements.

\section{References}

Bannerot, S. P., and C. B. Austin. 1983. Using frequency distributions of catch per unit effort to measure fish-stock abundance. Transactions of the American Fisheries Society 112:608-617.

Beverton, R. J. H., and S. J. Holt. 1957. On the dynamics of exploited fish populations. Fishery Investigations Series Il Marine Fisheries Great Britain Ministry of Agriculture Fisheries and Food 19.

Deriso, R. B. 1980. Harvesting strategies and parameter estimation for an age-structured model. Canadian Journal of Fisheries and Aquatic Science 37:268-282.

Dow, R. L., F. W. Bell, ANd D. M. Harriman. 1975. Bioeconomic relationships for the Maine lobster fishery with consideration of alternative management schemes. NOAA (National Oceanic and Atmospheric Administration) Technical Report NMFS (National Marine Fisheries Service) SSRF (Special Scientific Report Fisheries) 683.

Draper, N. R., AND H. SMith. 1980. Applied regression analysis. John Wiley and Sons, New York, New York, USA.

Fox, W. W., JR, 1970. An exponential surplus-yield model for optimizing exploited fish populations. Transactions of the American Fisheries Society 99:80-88.

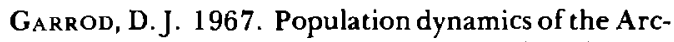
to-Norwegian cod. Journal of the Fisheries Research Board of Canada 24:145-190.

Graham, M. 1935. Modern theory of exploiting a fishery and application to North Sea trawling. Journal du Conseil, Conseil International pour l'Exploration de la Mer 10:264-274.

Holden, M. J. 1977. Elasmobranchs. Pages 187-215 in J. A. Gulland, editor. Fish population dynamics. John Wiley and Sons, New York, New York, USA.

Hutchinson, G. E. 1948. Circular causal systems in ecology. Annals of the New York Academy of Science 50:221-246.
JENSEN, A. L. 1976. Assessment of the United States lake whitefish (Coregonus clupeaformis) fisheries of Lake Superior, Lake Michigan, and Lake Huron. Journal of the Fisheries Research Board of Canada 33:747-759.

Jensen, A. L. 1978. Assessment of the lake trout fishery in Lake Superior: 1929-1950. Transactions of the American Fisheries Society 107:543549.

Jensen, A. L., and J. S. Marshall. 1982. Application of a surplus production model to assess environmental impacts on exploited populations of Daphnia pulex in the laboratory. Environmental Pollution Series A, Ecological and Biological 28: 273-280.

Jensen, A. L., and J. S. Marshall. 1983. Modelling population responses to toxicant induced mortality. Environmental Management 7:171-175.

Marchesseault, G. D., S. B. Salla, and W. J. Palm. 1976. Delayed recruitment models and their application to the American lobster (Homarus americanus) fishery. Journal of the Fisheries Research Board of Canada 39:1779-1787.

Pella, J. J., and P. K. Tomlinson. 1969. A generalized stock production model. Inter-American Tropical Tuna Commission Bulletin 13:419-496.

Ricker, W. E. 1954. Stock and recruitment. Journal of the Fisheries Research Board of Canada 11: 559-623.

RICKER, W. E. 1975. Computation and interpretation of biological statistics of fish populations. Fisheries Research Board of Canada Bulletin 191.

Russell, F. S. 1931. Some theoretical considerations on the "overfishing" problem. Journal du Conseil, Conseil International pour l'Exploration de la Mer 6:3-27.

SChaefer, M. B. 1954. Some aspects of the dynamics of populations important to the management of the commercial marine fisheries. Inter-American Tropical Tuna Commission Bulletin 1:27-56.

SCHAEFer, M. B. 1957. A study of the dynamics of the fishery for yellowfin tuna in the eastern tropical Pacific Ocean. Inter-American Tropical Tuna Commission Bulletin 2:247-268.

SCHNUTE, J. 1977. Improved estimates from the Schaefer production model: theoretical considerations. Journal of the Fisheries Research Board of Canada 34:583-603.

SHEPARD, M. P., AND F. C. WITHLeR, 1958. Spawning stock size and resulting production for Skeena sockeye. Journal of the Fisheries Research Board of Canada 15:1007-1025.

Silliman, R. P. 1968. Interaction of food level and exploitation in experimental fish populations. United States Fish and Wildlife Service Fishery Bulletin 66:425-439.

Silliman, R. P. 1971. Advantages and limitations of "simple" fishery models in light of laboratory experiments. Journal of the Fisheries Research Board of Canada 28:1211-1214.

Silliman, R. P. 1972. Effect of crowding on relation 
between exploitation and yield of Tilapia macrocephala. United States National Marine Fisheries Service Fishery Bulletin 70:693-698.

Silliman, R. P., and J. S. Gutsell. 1958. Experjmental exploitation of fish populations. United States Fish and Wildlife Service Fishery Bulletin 58:215-252.

WALTER, G. G. 1973. Delay-differential equation models for fisheries. Journal of the Fisheries Research Board of Canada 30:939-945.

WALter, G. G. 1978. A surplus production model incorporating recruitment and applied to a stock of Atlantic mackerel (Scomber scombrus). Journal of the Fisheries Research Board of Canada 35: 229-234.

VOLTERRA, V. 1928. Variation and fuctuations of the number of individuals in animal species living together. International Council for the Exploration of the Sea. Journal du Conseil, Conseil International pour l'Exploration de la Mer 3:151 . 